\title{
Fracture resistance of incisal tooth fragment reattached with different adhesive materials and retentive techniques
}

\author{
Fábio Herrmann Coelho-de-Souza ${ }^{a}$, Guilherme Fossáb ${ }^{b}$ Flávia Ávila Pereira ${ }^{c}$, Celso Afonso Klein-Júnior ${ }^{\text {, }}$ \\ Maria Carolina Guilherme Erhardt ${ }^{a}$, Thaís Thoméa
}

\begin{abstract}
OBJECTIVE: This study evaluated in vitro the shear bond strength of experimentally fractured human tooth fragments reattached with different adhesive materials and retentive techniques.

METHODS: Forty-eight sound mandibular incisors were randomly divided into 6 groups $(n=8)$. Their incisal edges were cut off in 5 groups, representing an enamel-dentin fracture. Intact teeth were used as control (Group 1). The fragment edges were reattached with adhesive system (Scotch Bond Multipurpose - 3M ESPE) (Group 2), adhesive system and composite resin (ICE - SDI) (Group 3), adhesive system and composite resin with circumferential bevel (Group 4), adhesive system and composite resin with internal dentin groove (Group 5), and adhesive system and composite resin with the circumferential bevel and internal dentin groove (Group 6). Shear bond strength was determined in a universal testing machine. Fracture modes were identified by light microscope. Kruskal-Wallis was used to analysis resistance to fracture and fracture patterns.

RESULTS: The results showed statistically significant differences $(p<0.05)$ among groups. The intact teeth (Group 1) showed higher fracture resistance than the other groups. Groups 2 and 6 did not differ and were statistically superior to other techniques. Group 4 presented statistically higher than in Group 5, which in turn was more resistant than Group 3.

CONCLUSIONS: None of the fragment reattachment techniques was able to achieve the strength of sound teeth. Fragments reattached only with adhesive system or with adhesive system and composite resin with the circumferential bevel and internal dentin groove showed the best performance for resistance to fracture.
\end{abstract}

Keywords: fragment reattachment; adhesive bonding; dental trauma, tooth fracture.

\section{Resistência à fratura de fragmentos dentários colados com diferentes materiais e técnicas}

\section{RESUMO}

INTRODUÇÃO: Este estudo analisou in vitro a resistência à fratura por cisalhamento de fragmentos dentários de incisivos inferiores humanos colados por diferentes técnicas

MÉTODOS: 48 incisivos inferiores hígidos foram divididos aleatoriamente em 6 grupos $n=8$ ). Cinco grupos tiveram os seus bordos incisais seccionados. Dentes hígidos foram usados como controle (Grupo 1). Os fragmentos dentários foram colados com sistema adesivo (Scotch Bond Multipurpose - 3M ESPE) (Grupo 2), sistema adesivo e resina composta (ICE - SDI) (Grupo 3), sistema adesivo e resina composta com técnica de bisel (Grupo 4), sistema adesivo e resina composta com técnica de canaleta (Grupo 5), sistema adesivo e resina composta com bisel e canaleta (Grupo 6). Todos os grupos foram submetidos ao ensaio de cisalhamento para avaliação da resistência à fratura dos fragmentos e os padrões de fratura foram identificadas em microscópio. A análise dos dados de resistência à fratura e dos padrões de fratura foi feita através de teste não-paramétrico de Kruskal-Wallis.

RESULTADOS: Os resultados encontrados demonstraram diferenças estatisticamente significativas $(p<0,05)$ entre os grupos. Dentes hígidos (Grupo 1) apresentaram maior resistência à fratura do que os demais grupos. Os Grupos 2 e 6 não diferiram entre si, e foram estatisticamente superiores às demais técnicas. O Grupo 4 apresentou resultados estatisticamente superiores ao Grupo 5, que por sua vez foi mais resistente do que o Grupo 3. CONCLUSÃO: Nenhuma das técnicas de colagem de fragmento foi capaz de atingir a resistência dos dentes hígidos. As técnicas de colagem de fragmento realizadas apenas com sistema adesivo ou com resina composta com a técnica de canaleta no fragmento associada ao bisel foram aqueles que apresentaram melhores desempenhos em relação à resistência a fratura.

Palavras-chave: colagem de fragmento; adesão; trauma dental; fratura dental. a Professor, Department of Conservative Dentistry, Universidade Federal do Rio Grande do Sul, Porto Alegre, Rio Grande do Sul, Brazil.

${ }^{\mathrm{b}}$ DDS, Private practice, Porto Alegre, Rio Grande do Sul, Brazil.

${ }^{c}$ DDS, Private practice, Porto Alegre, Rio Grande do Sul, Brazil.

d Professor, Department of Dentistry, Universidade Luterana do Brasil, Rio Grande do Sul, Canoas, Brazil.

Conflict of Interests: The authors state that there re no financial and personal conflicts of interest that could have inappropriately influenced their work.

Copyright: (C) 2017 Coelho-de-Souza et al.; licensee EDIPUCRS. 


\section{INTRODUCTION}

Coronal fractures of anterior teeth are the most common form of severe dental trauma, affecting mainly children and adolescents $[1,2]$. The majority of dental trauma involving anterior teeth affects the permanent maxillary incisors due to its position on the arc, followed by the mandibular central incisors and lateral incisors, in an order of incidence [3]. Several factors must be evaluated at the time of defining the treatment of these fractures, such as the extension of the fracture (with or without pulp exposure) and the pattern of the fracture (associated with an involvement of root and invasion of the periodontal biological width). Moreover, the presence or absence of the tooth fragment and its conditions of use, considering the adaptation between the fragment and the remaining structure, should also be assessed at the time of defining the limitations of treatments and thereby providing a good prognosis $[1,4]$.

The development of adhesive materials has enabled new perspectives in the rehabilitation of fractured teeth. One of the options for treatment of coronal fractures, especially when there is no violation of biological width, is the reattachment of the fragment with dental bonding techniques when the fragment is available. The reattachment of the fragment is currently the preferred technique for coronal fracture treatment [4], being a conservative alternative that offers a number of advantages, including improved aesthetics and function, maintain the original color of the tooth, and improve the psychological aspect of the patient, representing a method simple and low cost $[5,6]$ and anatomy restore a surface with improved wear resistance [7]. When the fractured fragment is available after an injury and if it is in good condition, the reattachment is the best treatment option [8].

Generally, the bond strength obtained in the reattachment of the fragment has not been as strong as the non-fractured teeth. Although, depending on the technique and the restorative material used for bonding, resistance to fracture can be improved and reach similar values than the nonfractured teeth [9]. Demarco et al. [6] observed that the materials used, and the technique used to prepare the tooth for reattachment may influence the shear bond strength of teeth. Reis et al. [4] highlighted the need for additional preparation (bevel or chamfer) to increase shear bond strength of the reattachment of the fragment. Evidence shows that among the main causes of failure of fragment reattachment, are further trauma and the use of the restored tooth with excessive chewing strength [10] which explains that many attempts have been made over the years in order to improve the shear bond strength on reattached teeth. Thus, in light of many published studies [11], it was found that for an effective teeth rehabilitation with fragment reattachment, both technical preparation and the type of material used for the reattachment $[4,11]$ can have significant effects on shear bond strength of these teeth.

The aim of this study was to evaluate and compare in vitro the shear bond strength of experimentally fractured human tooth fragments reattached with different adhesive materials and retentive techniques. The alternative hypothesis tested was that there was no difference among tooth fragment reattachment techniques in relation to shear bond strength.

\section{METHODS}

Forty-eight sound human mandibular incisors, extracted for periodontal reasons, were selected for the study. The ethical clearance for the use of extracted tooth was obtained from the institution ethical committee. Specimens were similar in size and free from cracks, caries lesions or structural defects. The teeth were cleaned from debris and calculus using metal curettes, disinfected in $10 \%$ formalin solution for 24 hours, and then stored in distilled water.

Control group was composed of 8 sound incisors. For the other teeth, the incisal edges were sectioned with a watercooled low-speed diamond saw, perpendicularly to the long axis of the tooth, representing an uncomplicated enameldentin fracture. Cuts were performed $4 \mathrm{~mm}$ from incisal edges. Teeth were then embedded in acrylic resin (JET Clássico) up to $1 \mathrm{~mm}$ from the cementoenamel junction. The teeth were randomly divided into six groups of 8 teeth each. The detailed procedures of fragment reattachment for each group are described below:

\section{G1 - Intact teeth}

Control group. Teeth remained intact (sound).

\section{G2 - Reattachment with adhesive system}

Fragment reattachment was performed with Scotch bond multipurpose adhesive system (3M ESPE, St. Paul, MN, USA) applied in both, the tooth and the fragment. The assembly was etched with $37 \%$ phosphoric acid selectively for 30 seconds on the enamel and then 15 seconds on the dentin. The etchant was rinsed with air/water spray and gentle air-dried. Primer was applied and gentle air-dried for 5 seconds. Then, the adhesive was applied and the fragment was adapted to the tooth. Excess adhesive was removed. Buccal and lingual surfaces were light cured for 40 seconds each with a LED curing light unit (Optilight Max Gnatus, Ribeirão Preto, SP, Brazil). The intensity of the light was monitored with a Curing Radiometer (Demetron/Kerr, Danbury, CT, USA), being above $600 \mathrm{~mW} / \mathrm{cm}^{2}$.

\section{G3 - Reattachment with adhesive system and composite resin}

Adhesive system (Scotch bond multipurpose) was applied as described for G2. The resin composite ICE A3 (SDI, Bayswater, Victoria, Aus) was applied in both fragment and the remaining tooth. After adaptation of the fragment to the tooth, excess composite was removed and light cured for 40 seconds on buccal and lingual surfaces.

G4 - Reattachment with adhesive system and composite resin with circumferential bevel

Fragment reattachment was initiated as previous group. After composite light curing, a $2 \mathrm{~mm}$ circumferential bevel 
was prepared in the tooth-fragment union with a spherical diamond bur 1014 (KG Sorensen, Alphaville, Brazil) using a high-speed handpiece. The bevel was cleaned with air/water spray and then etched with $37 \%$ phosphoric acid for $30 \mathrm{~s}$. Adhesive system (Scotch bond multipurpose) was applied to the bevel as previously described and light cured for $20 \mathrm{~s}$. Resin composite (ICE A3) was applied to the bevel and light cured for $40 \mathrm{~s}$ on buccal and lingual surfaces. Finishing and polishing was performed with silicon points Enhance (Dentsply, York, PA, USA).

\section{G5 - Reattachment with adhesive system and composite resin with internal dentin groove}

A $2 \mathrm{~mm}$-depth internal dentin groove was prepared in the fragment with a spherical diamond bur 1011 (KG Sorensen) using a high-speed handpiece. After cleansing with air/water spray, the adhesive system (Scotch bond multipurpose) was applied to the tooth and fragment, as previously described and light cured for $20 \mathrm{~s}$. Resin composite (ICE A3) was applied to the internal dentin groove in the fragment and to the fractured tooth. The fragment was adapted to the tooth, excess resin composite was removed and the interface was light cured for $40 \mathrm{~s}$ in each surface (buccal and lingual). Finishing and polishing were performed with silicon points (Enhance).

\section{G6 - Reattachment with adhesive system and composite resin with circumferential bevel and internal dentin groove}

Fragment reattachment was initiated as previous group. The internal groove was performed and adhesive system and resin composite were used to reattach the fragment to the tooth. After polymerization of the assembly toothfragment, a $2 \mathrm{~mm}$ circumferential bevel was prepared along the tooth-fragment union with a spherical diamond bur 1014 (KG Sorensen) with a high-speed handpiece. The bevel was cleaned with air/water spray and Adhesive system (Scotch bond multipurpose) and resin composite (ICE A3) were applied to the bevel as described for G4. Finishing and polishing were performed with silicon points (Enhance).

\section{Shear bond strength test}

All samples were subjected to a shear bond strength test in a Universal Testing Machine DL 2000 (EMIC, São
José dos Pinhais, PR, Brazil) for the analysis of resistance to fracture. A load perpendicular to the long axis of the teeth was applied to the incisal third of the buccal surface of each tooth through a sharp-edge stainless steel scalpel adapted to the machine. The force was applied at a crosshead speed of $0.5 \mathrm{~mm} / \mathrm{min}$. The load required to ultimate fracture teeth was measured in Newtons and recorded for all samples.

Fracture patterns were evaluated in stereoscopic microscope (KIOMA) at a magnification of $40 \mathrm{X}$, and classified into: 1) fracture of the tooth fragment, 2) fracture of the tooth, 3) adhesive fracture (at union tooth-fragment); 4) mixed fracture (default associable), 5) cohesive failure (resin composite).

\section{Statistical analysis}

Data analysis of the resistance to fracture and fracture patterns was performed using KRUSKAL-WALLIS test, with a significance level of $5 \%$. The differences between groups were identified by the multiple comparison tests of Student-Newman-Keuls.

\section{RESULTS}

The shear bond strengths values for the six groups were presented in Table 1. Table 2 indicates fracture patterns for the different groups.

Table 1. Data related to shear bond strengths test (values presented in Newtons).

\begin{tabular}{llcccc}
\hline \multicolumn{1}{c}{ Groups } & n & Median & 25\% & $75 \%$ & SNK \\
G1 (int) & 8 & 180,69 & 149,90 & 225,70 & A \\
G2 (ad) & 8 & 45,39 & 43,30 & 55,99 & B \\
G3 (ad+cr) & 8 & 12,17 & 9,73 & 17,21 & E \\
G4 (ad+be) & 8 & 26,43 & 17,04 & 48,34 & C \\
G5 (ad+dg) & 8 & 14,26 & 12,43 & 22,61 & D \\
G6 (ad+be+dg) & 8 & 35,37 & 32,01 & 50,70 & B \\
\hline
\end{tabular}

*SNK $=$ multiple comparison tests of Student - Newman - Keuls. Different letters illustrate statistical significance. int: intact teeth; ad: adhesive system; ad+cr: adhesive system + composite resin; ad +be: adhesive system + composite resin + circumferential bevel $\mathrm{ad}+\mathrm{dg}$ : adhesive system + composite resin + internal dentin groove; ad +be+dg: adhesive system + composite resin + circumferential bevel + internal dentin groove.

Table 2. Fracture patterns for tested groups.

\begin{tabular}{|c|c|c|c|c|c|c|c|}
\hline Groups & $\mathrm{n}$ & Adhesive & Mixed & Tooth Fracture & $\begin{array}{l}\text { Tooth Fragment } \\
\text { Fracture }\end{array}$ & Cohesive Failure & SNK \\
\hline G1 (int) & 8 & - & - & 8 & - & - & A \\
\hline G2 (ad) & 8 & 8 & - & - & - & - & C \\
\hline G3 $(\mathrm{ad}+\mathrm{cr})$ & 8 & 6 & 2 & - & - & - & C \\
\hline G4 (ad+be) & 8 & 2 & 5 & - & - & 1 & B \\
\hline G5 $(\mathrm{ad}+\mathrm{dg})$ & 8 & - & 6 & - & - & 2 & B \\
\hline G6 $(a d+b e+d g)$ & 8 & - & 7 & - & - & 1 & B \\
\hline
\end{tabular}

* SNK = multiple comparison tests of Student - Newman - Keuls. Different letters illustrate statistical significance. int: intact teeth; ad: adhesive system; ad +cr: adhesive system + composite resin; ad + be: adhesive system + composite resin + circumferential bevel; ad +dg: adhesive system + composite resin + internal dentin groove; ad +be + dg: adhesive system + composite resin + circumferential bevel + internal dentin groove. 
The results showed statistically significant differences $(p<0.05)$ among groups. Intact teeth (Group 1 - control) showed higher fracture resistance than other groups. The fragments bonded by the adhesive system technique (Group 2) and composite resin with bevel and internal dentin groove technique (Group 6) did not differ, and were statistically superior to other techniques. Group 4 (composite resin + bevel) presented statistically higher values for fracture resistance than Group 5 (composite resin + internal dentin groove), which in turn was more resistant than Group 3 (adhesive system + composite resin).

Results showed that Groups 2 and 3 (adhesive system and adhesive system with composite resin) concentrated their fracture patterns in adhesive failures. Groups 4, 5 and 6 (composite resin + circumferential bevel, composite resin + internal dentin groove and composite resin + circumferential bevel + internal dentin groove) had more mixed failures.

\section{DISCUSSION}

Fractures in primary or permanent teeth have been a major challenge for dentists, being considered as an emergency both in relation to the fracture itself, but also social and emotional changes experienced by patients $[12,13]$. However, advances in adhesive dentistry have allowed the dentist to use the tooth fragment to restore fractured teeth, making possible the fragment reattachment as an alternative to fractured tooth restoration [12].

The attachment of dental fragments is an important technique to restore fractured teeth, since it offers aesthetic and functional benefits [12]. Few studies have evaluated the shear bond strength depending on the technique used for fragments reattachment, and the results found have been quite varied [4].

Shear bond strength tests are an important tool for researchers as they allow a preliminary investigation on the behavior of the restorative materials and reattachment techniques [12]. Although in vitro studies cannot faithfully reproduce the oral environment, they represent important tools for predicting the behavior of materials and structures in the oral cavity. Considering the very high incidence of injuries in incisors, this study used human mandibular incisors to evaluate the fracture resistance for different bonding techniques used for tooth fragments reattachment.

Technical difficulties in the restoration of fractured teeth with composite resin as getting the color, shape, surface texture, translucency and durability appropriate, which include abrasion and discoloration process, are some of the disadvantages of this technique compared to the technique of fragment tooth collage [3,14].

When the tooth fragment is available and in good condition, the fragment bonding technique is a treatment option for highly functional and aesthetic results $[11,15]$. Fragment reattachment should obey the precepts of strict adhesion to enamel and dentin, using materials and techniques of modern adhesive dentistry [13]. Among the advantages of fragment bonding technique, one can cite the overall aesthetics immediate recovery, since the shape, contour, alignment, surface texture, and translucency are the natural tooth $[16,10]$, and allows maintenance of gingival contour and treatment in a single appointment [17]. In most cases where fragment collage is applied, aesthetics obtained is more durable since a small quantity of restorative material will be exposed on the buccal surface $[18,19]$. The function of the fractured tooth is also readily restored through the preservation of occlusal contacts identical to the originals, so that the physiological wear of the restored tooth is the same as presented by the adjacent teeth.

Some care must be taken with the fragment. It should be preserved intact, clean and hydrated until reattachment, favoring the immediate and aesthetic result $[18,19]$. Farik et al. [19] showed that there was a reduction of the bond strength between remnant and fragment when the latter is kept in a dry environment for more than 1 hour before reinsertion. In contrast, Ylmaz et al. [20] observed no statistically significant differences in fracture resistance between fragments that were kept in a dry place for 47 hours, to those who have been immersed in water for 24 hours before reinsertion. Regarding the clinical procedure of fragments reattachment can be emphasized that this is a safe, simple, fast and low cost procedure, generating emotional and social highly positive impact $[13,16,10]$.

The direct reattachment of the fragment, with only application of the adhesive system in combination or not with an intermediate material is less invasive techniques available for bonding fragments. The degradation of the composite in the oral environment is well documented in the literature [21], abrasion and discoloration of the material, as well as union composite/tooth structure, may occur over time [13].

Many kinds of restorative materials and dentin-bonding agents could be employed for fragment reattachment $[4,22]$. When the fractured teeth present dentin exposure, it is preferable to use the total etching adhesive system [23] occurring effective hybridization between the dentin and the adhesive, significantly increasing the shear bond strength $[13,23]$ such as was found in this study. However, in some situations of trauma, where the exposed dentin at the fractured surface is very deep and close to the pulp, the use of self-etching could be more appropriate, due to the reduced risk of post-operative sensitivity [14].

The lack of need for a bevel can be supported by the improvement of bonding agents (adhesive system), as the mechanical integrity can stay be maintained for long time $[13,24]$. However, we must point out the numerous advantages that the use of the bevel can bring to the restorative procedure. The bevel can help mask the interface tooth/restorative material, provide a higher marginal sealing of the restoration, increase energy surface, remove the layer of non-prismatic enamel and increase the bonding surface area $[4,6,12]$.

In the present study, human tooth fragments were made from a cut perpendicularly to the long axis of the tooth, $4 \mathrm{~mm}$ from incisal edges [6]. In this technique, the arrangement 
of enamel rods are not the same as in a fractured tooth, which may influence the bond strength as demonstrated by Loguercio et al. [25]. The authors found different values of bond strength fractured teeth in comparison with those cut with a diamond blade.

All samples in the present study were subjected to a shear bond strength test in a universal testing machine for the analysis of resistance to fracture. A load perpendicular to the long axis of the teeth was applied to the incisal third of the buccal surface of each tooth through a sharp-edge stainless steel scalpel adapted to the machine [6]. The speed used was set at $0.5 \mathrm{~mm} / \mathrm{min}$, as this value is usually used in similar tests $[15,14,11]$.

In the present study, none of the collage techniques tested showed equal or superior fracture resistance values to those in the control group (sound teeth). Group 2 (adhesive system) and Group 6 (adhesive system + composite resin + bevel + groove) did not differ, and were statistically superior to the other bonding techniques. The results presented by Reis et al. [11], show that the collage of fragments with the technique of circumferential bevel along with internal groove in the fragment resulted in bond strength similar to the ones found for sound teeth, and the increase in the resistance to fracture is due to obtain a larger bond area after preparation.

Reis et al. [15] have shown that fragments bonded with adhesive system without tooth preparation presented shear bond strength significantly lower than the fragments reattached with the bevel technique. However, there are also reports of success in reattachments performed only with adhesive system, without bevel or internal groove [26]. Studies have found similar shear bond strength among intact teeth and teeth with fragments reattached, even when they were reattached with adhesive system only, as presented in this study [7,27].

The disparity of results among laboratorial studies may be due to different methodologies used, such as the type of mechanical test, the speed of load application, the origin of teeth (human, bovine or porcine), the method of obtaining fragments, the pattern and extent fracture, technique and materials used for bonding $[12,28]$, and the fragment store media [29]. Thus, it is debatable whether or not to perform some type of preparation in the tooth or in the fragment $[4,6,24]$. A reattachment performed using only the adhesive system seems to be a less invasive and more effective technique [10,25].

Regarding the fracture patterns, Groups 2 and 3 (adhesive system and adhesive system + composite resin) had more adhesive failures and Groups 4, 5 and 6 (composite resin with bevel, composite resin with groove, resin composite with bevel and groove) had more mixed failures, corroborating with the findings by Bruschi-Alonso et al. [14].

Given the results presented here it is important to address the need for further studies following this line of research due to the many variables related to the materials employed and the techniques used. When evaluating the shear bond strength of dental fragments after reattachment, we are analyzing not only the behavior of these materials against the resistance as well as the protocols for implementing the techniques and may perhaps contribute to the improvement of the same as well as the emergence other. Given the above it is evident the current concern of Dentistry in seeking what is best for the patient, accommodating a correct diagnosis of these clinical situations with the resources available for treatments, aiming to return the form, aesthetics, function and dental elements primarily to the health patient.

\section{CONCLUSION}

Based on the results of this study, it could be concluded that none of the fragment reattachment techniques was able to achieve the strength of sound teeth; and fragments reattached only with adhesive system or with adhesive system and composite resin with circumferential bevel and internal dentin groove showed the best performance for resistance to fracture.

\section{REFERENCES}

1. Andreasen JO, Ravn JJ. Epidemiology of traumatic dental injuries to primary and permanent teeth in a Danish population sample. Int J Oral Surg 1972;1:235-9. https://doi.org/10.1016/S0300-9785(72)80042-5

2. Andreasen FM, Andreasen JO. Crown fractures. In: Andreasen FM Andreasen JO. Textbook and color atlas of traumatic injuries to the teeth. Copenhagen, Denmark: Mosby; 1994. p. 219-56.

3. Pusman E. Fracture resistance of tooth fragment reattachment: effects of different preparation techniques and adhesive materials. Dent Traumato 2010;26:9-15. https://doi.org/10.1111/j.1600-9657.2009.00855.x

4. Reis A, Loguercio AD, Kraul A, Matson $E$. Reattachment of fractured teeth: a review of literature regarding techniques and materials. Oper Dent 2004;29:226-33

5. Andreasen FM, Norém JG, Andreasen JO, Engelhardtsen S, LindhStrömberg U. Long-term survival fragment bonding in the treatment of fractured crows: a multicenter clinical study. Quintessence Int 1995; 26:669-81

6. Demarco FF, Fay RM, Pinzon LM, Powers JM. Fracture resistance of reattachment coronal fragments: influence of different adhesive materials and bevel preparation. Dent Traumatol 2004:20:157-63. https://doi. org/10.1111/j.1600-4469.2004.00221.x

7. Farik B, Munksgaard EC, Kreiborg S, Andreasen JO. Adhesive bonding of fragment anterior teeth. Endod Dent Traumatol 1998; 14:119-23. https:// doi.org/10.1111/j.1600-9657.1998.tb00823.x

8. Baratieri LN, Ritter AV, Monteiro Junior S, de Mello Filho JC. Tooth fragment reattachment: an alternative for restoration of fractured anterior teeth Pract Periodontics Aesthet Dent 1998; 10:115-25.

9. Badam AA, Dunne SM, Scheer B. An in vitro investigation into the shear bond strengths of two dentine bonding agents used into reattachment of incisal edge fragments. Endod Dent Traumatol 1995;129-35. https://doi. org/10.1111/j.1600-9657.1995.tb00474.X

10. Maia EA, Baratieri LN, de Andrada MA, Monteiro S Jr, de Araújo EM Jr. Tooth fragment reattachment: fundamentals of the technique and two case reports. Quintessence Int 2003:34:99-107.

11. Reis A, Francci C, Loguercio AD, Carrilho MR, Rodrigues Filho LE. Reattachment of anterior fractured teeth: fracture strength using different techniques. Oper Dent 2001;26:287-94

12. Campos RE, Soares CJ, Oliveira-Junior OB, Silva GR. Influence of the chamfer on the bonding strength of reattached dental fragments. Robrac. 2006;15(39):44-50.

13. Papa AMC, Sacramento PA, Puppin-Rontani RM. Direct reattachment of fracture teeth. Rev Odontol UNESP. 2008:37(3):217-22.

14. Bruschi-Alonso RC, Alonso RC, et al. Reattachment of anterior fractured teeth: effect of materials and techniques on impact strength. Dent Traumatol 2010;26:315-22. https://doi.org/10.1111/j.1600-9657.2010.00906.x

15. Reis A, Kraul A, Francci $C$, de Assis TG, Crivelli DD, Oda M, et al. Reattachment of anterior fractured teeth: fracture strength using different materials. Oper Dent. 2002;27:621-7. 
16. Kanca J.Replacement of a fractured incisor fragment over pulpal exposure: a long-term case report. Quintessence Int. 1996;27:829-32

17. Wadhwani CPK. A single visit multidisciplinary approach to the management of traumatic tooth crown fracture. Br Dent J. 2000;188: 593-8. https://doi.org/10.1038/sj.bdj.4800548a

18. Yilmaz $Y$, Zehir $C$, Eyuboglu O, Belduz N. Evaluation of success in the reattachment of coronal fractures. Dent Traumatol 2008;24:151-8. https:// doi.org/10.1111/j.1600-9657.2007.00532.x

19. Farik B, Munksgaard EC, Andreasen JO, Kreiborg S. Drying and rewetting anterior crown fragments prior to bonding. Endod Dent Traumatol 1999; 15:113-6. https://doi.org/10.1111/j.1600-9657.1999.tb00766.x

20. Yilmaz Y, Guler C, Sahin H, Ozge E. Evaluation of tooth-fragment reattachment: a clinical and laboratory study. Dent Traumatol 2010;26: 308-14. https://doi.org/10.1111/j.1600-9657.2010.00907.x

21. Correr GM, Bruschi Alonso RC, Correr Sobrinho L, Puppin-Rontan $\mathrm{RM}$, Ferracane JL. In vitro wear of resin-based materials--simultaneous corrosive and abrasive wear. J Biomed Mater Res B Appl Biomater. 2006; 78:105-14. https://doi.org/10.1002/jbm.b.30461

22. Wiegand A, Rodig T, Attin T. Treatment of crown fractured incisors: reattachment instead of restoration? Review. Schweiz Monatsschr Zahnmed. 2005:115:1172-81.

23. Nakabaiashi N. Adhesive bonding with 4-META - Review. Oper Dent. 1992 (Suppl 5):125-30
24. Dorignac G, Nancy J, Griffiths D. Bonding of natural fragments to fractured anterior teeth. J Pedod. 1990;14:132-5.

25. Loguercio AD, Mengarda J, Amaral R, Kraul A, Reis A. Effect of fractured or sectioned fragments on the fracture strength of different reattachment techniques. Oper Dent. 2004;29(3):295-300.

26. Perdigão J, Gerardeli S. Bonding characteristics of self-etching adhesives to intact versus prepared enamel. J Esthet Rest Dent. 2003;15(1):32-42. https://doi.org/10.1111/j.1708-8240.2003.tb00280.x

27. Farik B, Munksgaard EC, Andreasen JO, Kreiborg S. Fractured teeth bonded with dentine adhesives with and without unfilled resin. Dent Traumatol 2002;18(2):66-9. https://doi.org/10.1034/j.1600-9657.2002.180203.x

28. Singhal R, Pathak $A$. Comparison of the fracture resistance of reattached incisor tooth fragments using 4 different materials. J Indian Soc Pedod Prev Dent, 2012;30(4):310-6. https://doi.org/10.4103/0970-4388. 108927

29. Shirani F, Sakhaei Manesh V, Malekipour M. Preservation of coronal tooth fragments prior to reattachment. Aust Dent J, 2013;58(3):321-5. https:// doi.org/10.1111/adj.12092 